IMSc scientists and give series of seminars and colloquia. Over the years the Institute has been privileged to have several Nobel Laureates and Fields Medalists among its distinguished visitors.

\title{
Academic Meetings
}

Besides the regular seminar/colloquium activities by the members of the Institute and the visiting scientists, workshops/symposia/conferences in various fields are being organized frequently by the Institute. The conference participants come from all over India and abroad. The Institute takes part in the Theoretical Physics Seminar Circuit (TPSC) programme under which scientists can visit leading research centres in India and lecture on their work. IMSc is actively participating in advanced schools like those conducted by the Science and Engineering Research Council (SERC) of the Department of Science and Technology (DST) and the National Board for Higher Mathematics (NBHM). The Institute actively encourages its members to collaborate with scientists elsewhere, and provides all required help to enable this.

The Institute of Mathematical Sciences

Central Institutes of Technology (C.I.T.) Campus

Tharamani, Chennai 600113 , Tamilnadu, India.

Telephone: (044) 235 1856, 235 0588; Fax: (044) 2350586

E-mail: office@imsc.ernet.in; URL: http://www.imsc.ernet.in

R Fagannathan

IMSc, Chennai, India

\section{Errata}

In Resonance, Vol.3, No.11, November 1998

p. 77 - subsection caption should read 'The Inert Pair Effect'.

p.78 - Table 1, first set of entries 'antagonistic' should read as 'agonistic' in three places.

In Resonance, Vol.3, No.12, December 1998

Replace ' $\mathrm{mm}$ ' by ' $\mu \mathrm{m}$ ' in the following lines

p. 9 - fourth line from bottom

p. 10 - second highlighted text

p.11- fourth line from top. 